\title{
Survival and Prognostic Factors After Carotid Artery Stenting in Patients with Concomitant Coronary Disease
}

\author{
Georgi Goranov ${ }^{1,2^{*}}$, M. Tokmakova ${ }^{1,2}$, P. Nikolov ${ }^{1,2}$ \\ ${ }^{1}$ Department of $1^{\text {st }}$ Internal Disease, Medical University of Plovdiv, Plovdiv, Bulgaria; ${ }^{2}$ Clinic of Interventional Cardiology, St. \\ George Multiprofile Hospital for Active Treatment, Plovdiv, Bulgaria
}

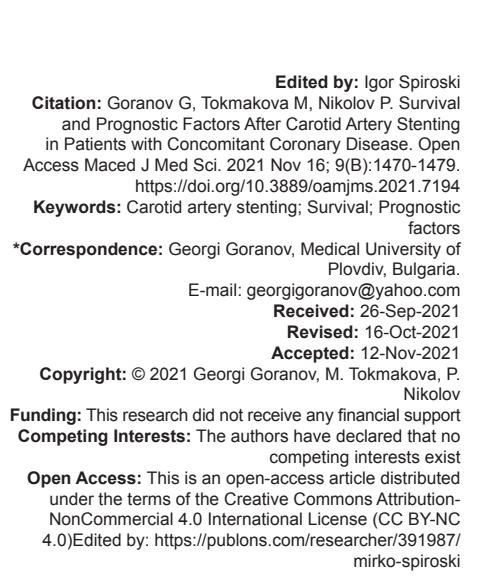

Abstract

: The aim of the study was to analyze the prognostic factors in patients after carotid artery stenting (CAS)

METHODS: In 329 patients after CAS, the median survival (MS) and overall survival (OS) were calculated for a follow-up period of 2-101 months. All patients underwent coronary angiography before carotid stenting and, if indicated, coronary revascularization. Four groups of factors were analyzed: Carotid disease, coronary artery disease (CAD), underlying cardiac pathology, and concomitant diseases.

RESULTS: MS in all patients was 86 months, OS at 1, 3, 5, and 9 years was - $94 \%, 85 \%, 73 \%$, and $51 \%$, respectively. Event free survival was 85 months. Log Rank-Mantel-Cox analysis demonstrated significantly reduced MS in 21 tested factors, most of them related to CAD. Two-step multifactorial Cox regression analysis defined only 7 of them as independent prognostic factors for the survival of patients after CAS: Left main stenosis, complete revascularization, late myocardial infarction, stroke, age over 70 years, valvular disease, and carotid score.

CONCLUSION: Survival of patients after CAS is limited mainly by CAD and underlying cardiac pathology. Staged revascularization treatment strategy may improve the prognosis and survival of patients with both carotid and coronary disease.

\section{Introduction}

Carotid atherosclerosis is one of the leading causes of neurological morbidity and mortality. About $87 \%$ of strokes are ischemic, $30 \%$ of which are caused by atherosclerotic plaque in the carotid arteries resulting in stenosis and/or thrombosis in the aforementioned. Thromboembolism of $50-99 \%$ stenosis of the internal carotid artery is the cause of approximately $10-15 \%$ of strokes in adults [1], [2], [3]. Carotid stenosis above 50\% occurs in a very wide range of people among the general population, but progresses markedly with age: In patients over and under 70 it is, respectively, $12.5 \%$ and $4.8 \%$ in men, and $6.9 \%$ and $2.2 \%$ in women [4], [5]. The characteristic localization and predilection site for stenosis is the carotid bifurcation and the ostium of the internal carotid artery. In clinical terms, carotid stenoses (CS) are defined as symptomatic, asymptomatic, and hemodynamically significant $(>70 \%$ in 2 projections). For about 2 years, high-grade (>70\%) asymptomatic CS progressed to thrombosis in $29 \%$ of patients, with $60 \%$ of them manifesting clinically (symptomatic stenosis) in the form of transient ischemic attack and stroke [1]. The relative risk of ischemic stroke in asymptomatic CS over $50 \%$ is 2.0 , and triples in patients with stenosis above $75 \%$. A characteristic feature of the atherosclerotic process is its progression with involvement of various vascular areas [6], [7]. According to the $\mathrm{REACH}$ register (Reduction of Atherothrombosis for Continued Health) about $40 \%$ of patients with cerebrovascular disease have multifocal vascular involvement, clinically manifested by coronary heart disease (CHD) and/or peripheral artery disease (PAD) [8]. In the studies of Hertzer et al. and Cohen et al., on CHD coronary stenosis was reported in $37 \%$ of patients with carotid endarterectomy (CEA) [9], [10], and according to Pieniazek et al. and Hofman et al. in $66-77 \%$ [11], [12]. The combination of coronary and carotid atherosclerosis is an unfavorable prognostic factor, and myocardial infarction (MI) and cardiac pathology in general are the most common causes of death after carotid revascularization [8]. Considering all of the above, the prognostic factors for patient survival after carotid and coronary revascularization, as well as the choice of the optimal strategy are a debatable issue. The aim of this study is to analyze the unfavorable prognostic factors for survival in patients with carotid and 
concomitant coronary atherosclerosis after stepwise interventional revascularization.

\section{Patients and Methods}

A prospective study followed 329 patients referred for carotid artery stenting (CAS). The average observation period was $40.9 \pm 27.6$ months (May 2011-Sep 2019). The male:female ratio was 253 (76.9\%): 76 (23.1\%) with a mean age of 70 years (ranged $45-88$ years). Patients with symptomatic carotid stenosis $>50 \%$ and patients with asymptomatic carotid stenosis $>70 \%$ were selected, assessed according to the NASCET criteria, with degree of stenosis classified according to a newly proposed score system. All patients underwent one-stage selective coronary and carotid angiography and, if indicated, coronary revascularization before CAS. CHD was assessed by means of Syntax and Gensini score systems. Revascularization procedures - percutaneous coronary intervention $(\mathrm{PCl})$ /coronary artery bypass grafting $(\mathrm{CABG})$ and $\mathrm{CAS}$, including bilateral carotid revascularization were performed in separate stepby-step procedures. In CAS, self-expandable stents with mandatory distal protection device - distal filter were implanted. All patients received dual antiplatelet therapy (Clopidogrel + Aspirin) and statins. Patients were monitored intra- and post-procedurally, on day 30 , at the $1^{\text {st }}$ year mark, and until the end of the follow-up for the frequency and characteristics of early and late complications, as well as fatal outcome of any cause. The revascularization procedures and the standard panel tests were performed in certified interventional units and laboratories at a university hospital. For the purpose of the study, the relationship between the four groups of factors (carotid disease, $\mathrm{CHD}$, underlying heart pathology, and concomitant diseases) and the registered peri- and post-procedural complications was sought. The data were processed using the statistical programs IBM SPSS, V 26 (2018), MedCalc V 19.0.7 (2019) and Minitab V 18.1 (2017). Two-step Kaplan-Meier, Log rank test, and two-step (2 blocks) multifactor Cox regression analysis were used to assess survival and prognostic factors.

\section{Results}

\section{General risk profile of patients}

With a significant predominance of males (76.9\%), $88.8 \%$ of patients were over 60 years of age, and their relative share was highest in the 69-78 age groups (43.2\%). The analysis of the main risk factors for atherosclerosis, comorbidity and in particular concomitant cardiocerebral and other vascular pathology shows that $100 \%$ of patients were hypertensive, every second patient was overweight $(58.1 \%)$ or a smoker $(56.8 \%)$, every third patient had diabetes mellitus $(33.4 \%)$ or hyperlipidemia $(31.1 \%)$ (Table 1).

Table 1: Main risk factors for atherosclerosis

\begin{tabular}{llll}
\hline Risk factors & Males \% & Females \% & Total \% \\
\hline Hypertension & $253(100.0)$ & $76(100.0)$ & $329(100.0)$ \\
Age above 70 & $147(58.1)$ & $46(60.5)$ & $193(58.3)$ \\
Overweight & $142(56.1)$ & $49(64.5)$ & $191(58.1)$ \\
Smoking & $151(65.6)$ & $36(47.4)$ & $187(56.8)$ \\
Diabetes & $78(30.8)$ & $32(42.1)$ & $110(33.4)$ \\
Hypertriglyceridemia & $73(28.5)$ & $23(30.3)$ & $96(31.1)$ \\
Hypercholesterolemia & $55(21.7)$ & $17(22.4)$ & $72(22.6)$ \\
CKD & $51(20.2)$ & $15(19.7)$ & $66(20.1)$ \\
COPD & $12(4.7)$ & $8(10.5)$ & $20(6.1)$ \\
Anemia & $8(3.2)$ & $6(7.9)$ & $14(4.4)$ \\
\hline CKD: Chronic kidney disease, COPD: Chronic obstructive pulmonary disease.
\end{tabular}

In $90.9 \%$ of patients concomitant CHD was established, 39.8\% had heart failure (HF), 38.6\% had suffered MI, and $38.0 \%$ - ischemic stroke (Table 2).

Given the above information 287 (87.2\%), patents were classified as high-risk and $42(12.8 \%)$ standard risk patients refused surgical treatment.

\section{Median survival (MS) rate}

The MS for the entire cohort for the observation period was 86 months (Kaplan-Meier and Log-rank test). High-risk patients had MS of 83 months, while, that is, the standard risk group MS was unattainable - $\chi^{2}$ $=6.683, p=0.010$ (Figure 1).

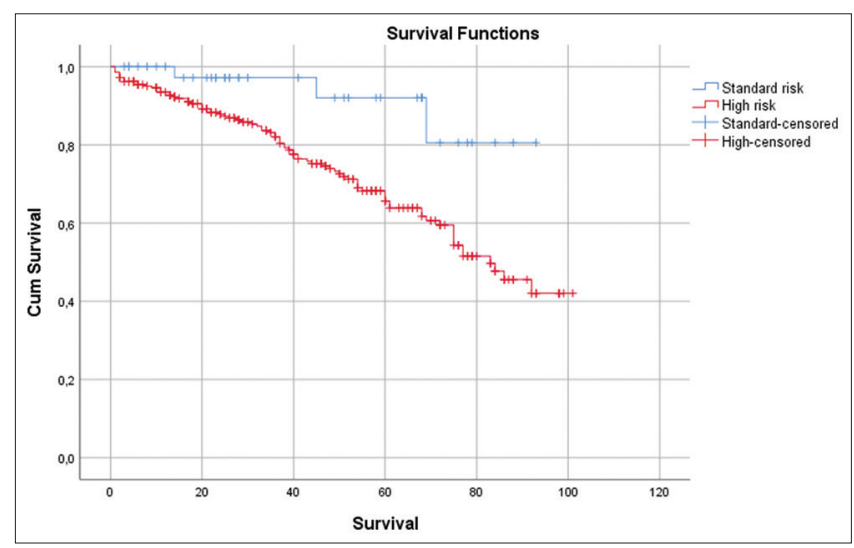

Figure 1: Risk profile and survival rate

\section{Survival prognostic factors}

\section{Carotid artery disease}

\section{Carotid score}

The degree of CS was assessed by means of specifically designed carotid score, as a sum of points for the two carotid arteries: 0 points for 
Table 2: Concomitant cardiovascular disease

\begin{tabular}{|c|c|c|c|c|c|c|c|}
\hline \multirow[t]{2}{*}{ Cardiovascular disease } & \multicolumn{3}{|l|}{ Male (253) } & \multicolumn{3}{|c|}{ Female (76) } & \multirow[t]{2}{*}{ Total (329) } \\
\hline & Total & $<70$ years & $>70$ years & Total & $<70$ years & $>70$ years & \\
\hline $\mathrm{CHD}$ & $237(93.7)$ & $127(50.2)$ & $110(43.5)$ & $62(81.6)$ & $27(35.5)$ & $35(46.1)$ & $299(90.9)$ \\
\hline Ischemic stroke & $106(42.1)$ & $62(24.6)$ & $44(17.5)$ & $21(27.6)$ & $6(7.9)$ & $15(19.7)$ & $127(38.6)$ \\
\hline Pacemaker & $19(7.5)$ & $1(0.4)$ & $18(7.1)$ & $3(3.9)$ & $1(1.3)$ & $2(2.6)$ & $22(6.7)$ \\
\hline Valvular heart disease & $73(29.0)$ & $25(9.9)$ & $48(19.0)$ & $20(26.3)$ & $5(6.5)$ & $15(19.7)$ & $93(28.3)$ \\
\hline FA & $32(12.6)$ & $10(4.0)$ & $22(8.7)$ & $6(7.9)$ & $1(2.9)$ & $5(12.2)$ & 38 (11.6) \\
\hline $\mathrm{HF}$ & $108(42.7)$ & $44(17.4)$ & $64(25.3)$ & $23(30.3)$ & $9(11.8)$ & $14(18.4)$ & $131(39.8)$ \\
\hline Hypertension & $253(100.0)$ & $133(52.6)$ & $120(47.4)$ & $76(100.0)$ & $35(46.1)$ & 41 (53.9) & $329(100.0)$ \\
\hline Renal stenosis & $4(1.6)$ & $3(1.2)$ & $1(0.4)$ & $3(3.9)$ & $2(2.6)$ & $1(1.3)$ & $7(2.1)$ \\
\hline PAD & $48(19.0)$ & $30(11.9)$ & $18(7.1)$ & $5(6.6)$ & $3(3.9)$ & $2(2.6)$ & $53(16.1)$ \\
\hline Past ischemic stroke & $103(40.7)$ & $56(22.2)$ & $47(18.6)$ & $22(28.9)$ & $11(14.4)$ & $11(14.4)$ & $125(38.0)$ \\
\hline
\end{tabular}

PAD: Peripheral artery disease, HF: Heart failure, CHD: Coronary heart disease, FA: Atrial fibrillation.

plaque of $0-29 \%, 1$ point for low-grade stenosis of 30-49\%, 2 points for moderate stenosis - 50-69\%, 3 points for high/critical $70-95 \%$ stenosis, 4 points for subtotal occlusion - 95-99\%, and 5 points for total occlusion $-100 \%$. The mean carotid score of the patients was 4.2 points with a significant predominance of score $3(40.1 \%)$, which corresponds to a high-grade/critical stenosis of $70-95 \%$ (Figure 2). The MS for the group with a high carotid score of 5-9 points was 75 months, while in patients with a carotid score of 1-4 points MS was unattainable $\left(\chi^{2}=6.731, p=0.009\right)$ (Figure 3$)$.

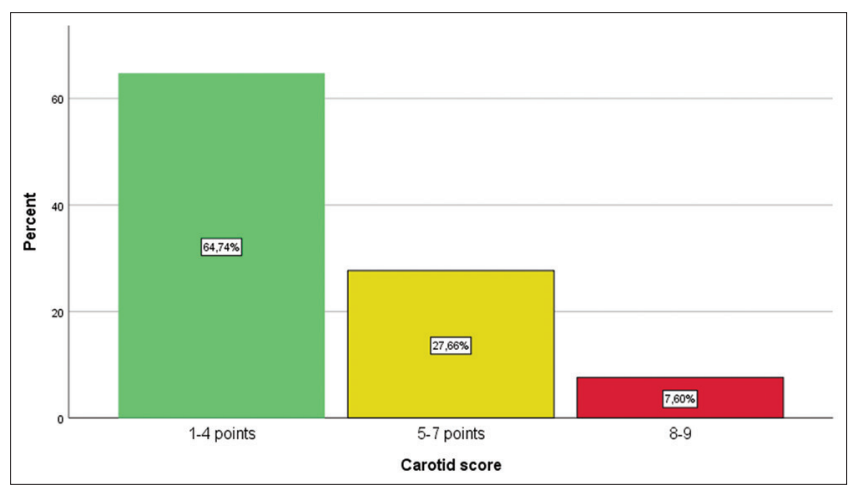

Figure 2: Carotid score distribution

Bilateral carotid stenosis and symptomatology

The presence of bilateral CS significantly reduces $\mathrm{MS}$, the aforementioned being unattainable in unilateral stenosis $\left(\chi^{2}=6.118, p=0.013\right)$ (Figure 4). The MSR in patients with symptomatic stenosis was 77.0 months and did not significantly differ from the MSR of asymptomatic CS p = 0.134 (Figure 5).

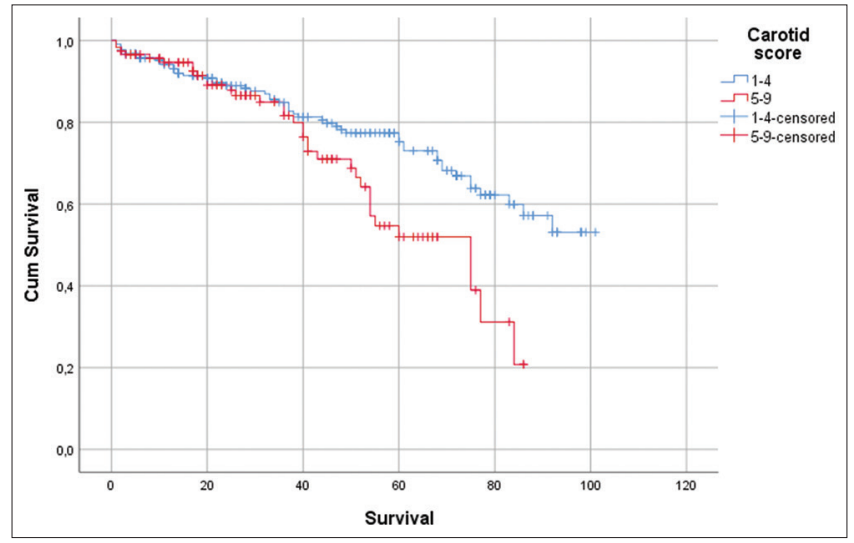

Figure 3: Carotid score and survival rate

\section{Previous strokes}

A significant factor for reduced survival was a previous stroke before CAS, with MS of 75.0 months compared to unattainable MS in patients without the previous ischemic stroke $\left(\chi^{2}=4.762, p=0.029\right)$ (Figure 6).

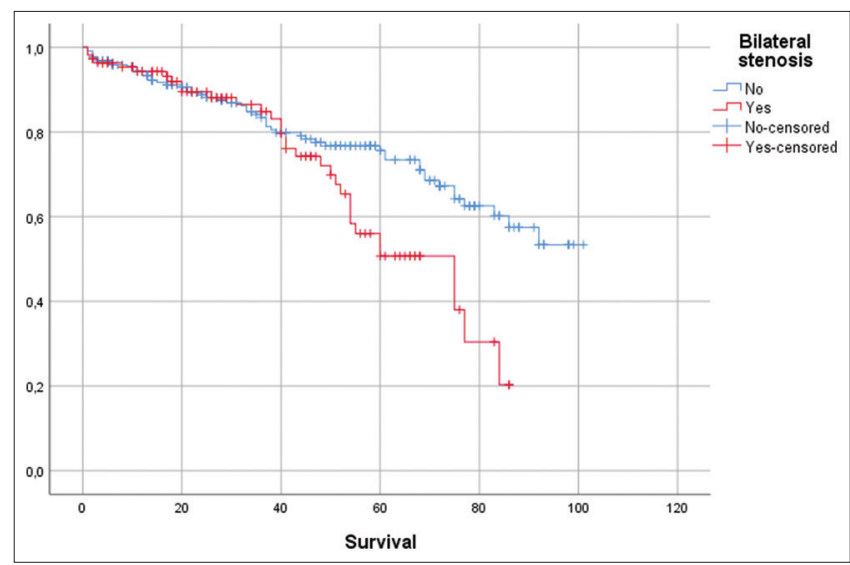

Figure 4: Bilateral carotid stenosis and median survival

\section{Other factors}

We did not find a relationship between patient survival and the type of implanted carotid stent $(p=0.311)$ or carotid restenosis $(p=0.447)$.

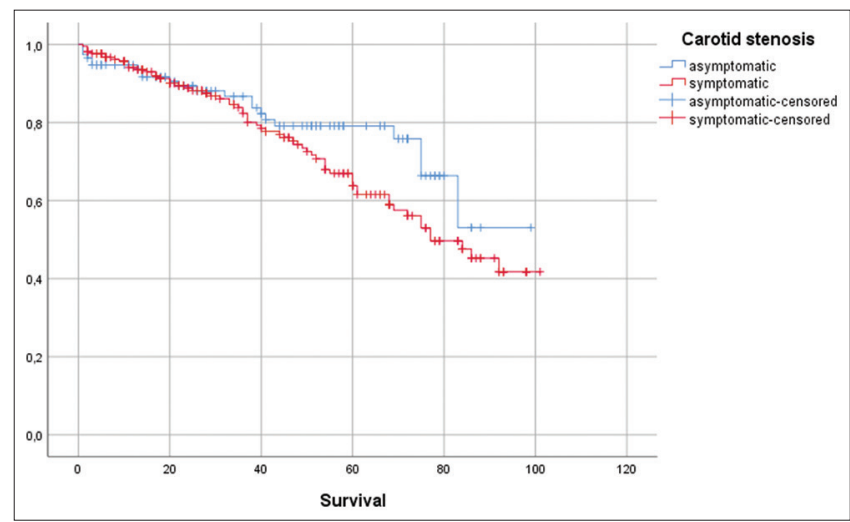

Figure 5: Symptomatic carotid stenosis and median survival

\section{CHD}

The MS for patients without concomitant CHD was unattainable, compared to 84 months 
in the presence of such $\left(\chi^{2}=3.121, p=0.077\right)$ (Figure 7).

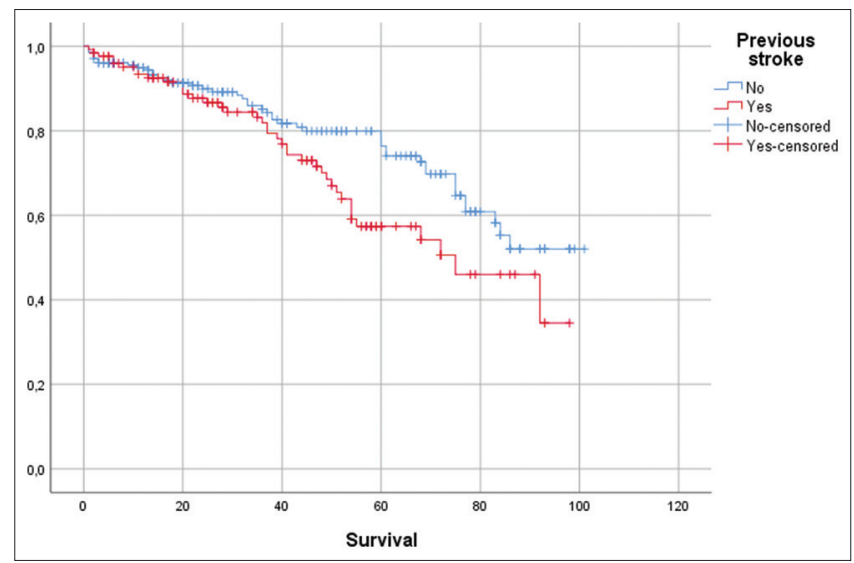

Figure 6: Ischemic stroke and survival

MS was significantly lower in patients with left main (LM) disease - 54.0 months, while in patients without LM disease the MSR was unattainable $-\chi^{2}=$ $30.188, p<0.001$ (Figure 8).

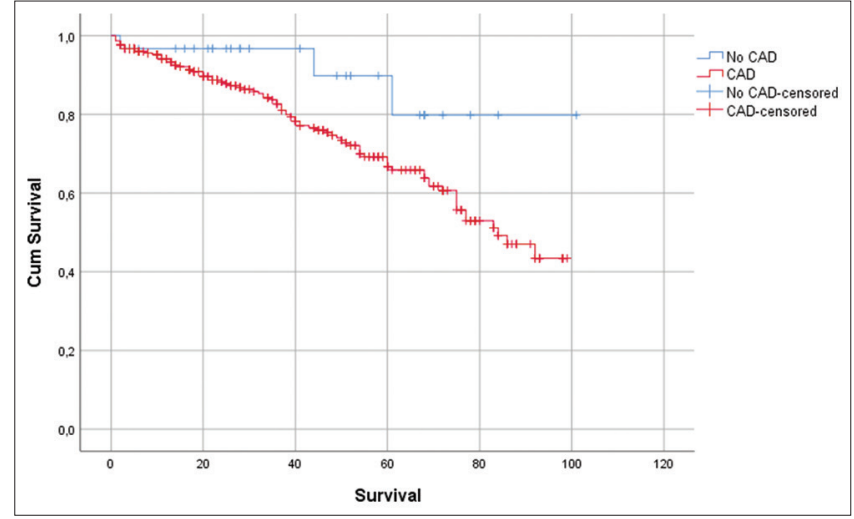

Figure 7: Coronary heart disease and median survival

\section{Coronary score systems}

The two score systems are generally not used as indicators of survival, but rather to assess coronary stenosis and select a revascularization strategy. However, the MS of patients with Gensini score $>70$ was 68 months, while in patients with Gensini score $<70$ MSR was unattainable $\left(\chi^{2}=\right.$ 17.860, $p=0.000$ ) (Figure 9). The MSR for Syntax score $>32$ was only 55 months compared to a MSR of 83 months for Syntax score <23 (Log Rank MantelCox $p<000)$ (Figure 10). What felt surprising was data on the discontinuity of the curves in patients with intermediate Syntax score 23-32 and the most favorable Syntax score $<23$, which turned out to have a lower survival rate. In this group the incidence of death from other causes, mainly malignant diseases, was the highest - $26(21.3 \%)$.

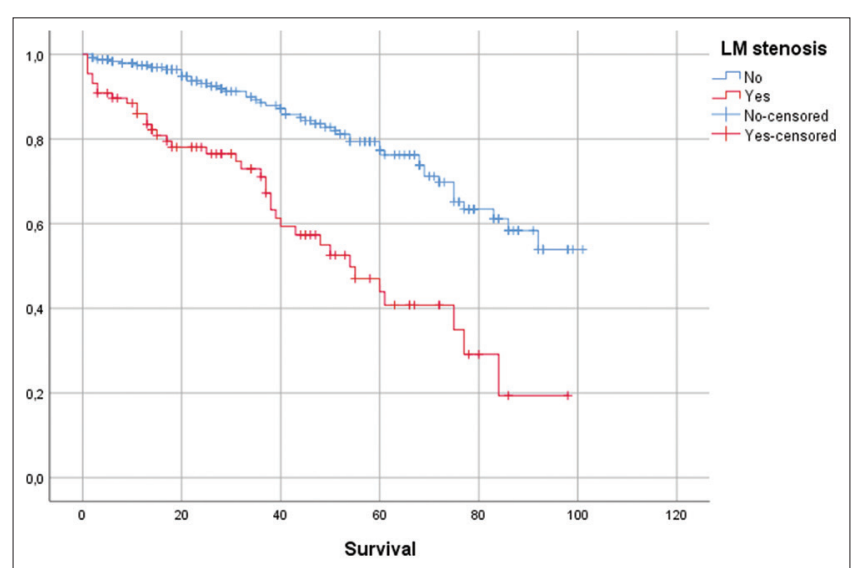

Figure 8: Left main disease and median survival

Quality/degree of revascularization and re-intervention

MSR in patients with repeat coronary revascularization and without re-PCI did not show

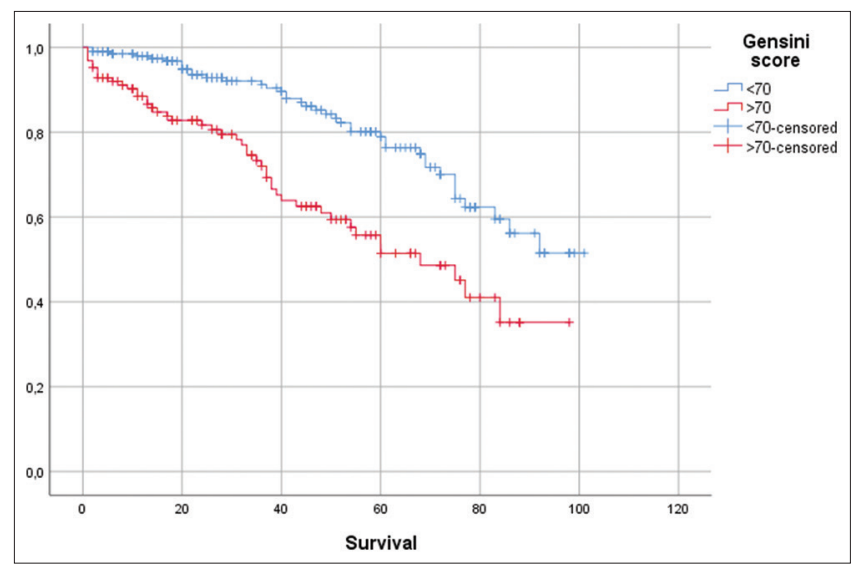

Figure 9: Gensini score and survival

statistically significant difference, 80.3 months survival in the re-intervention group compared to 69.9 months in patients with a single procedure (Figure 11).

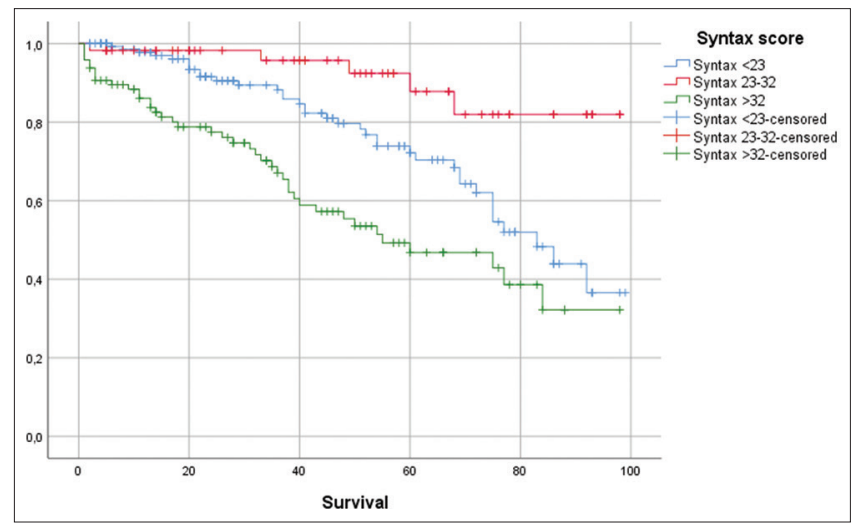

Figure 10: Syntax score and survival

It is important to point out that MS in patients with complete coronary revascularization was unattainable compared to the group with incomplete revascularization with MS of only 38 months $\left(\chi^{2}=28.215, p<0.000\right)$ (Figure 12). 


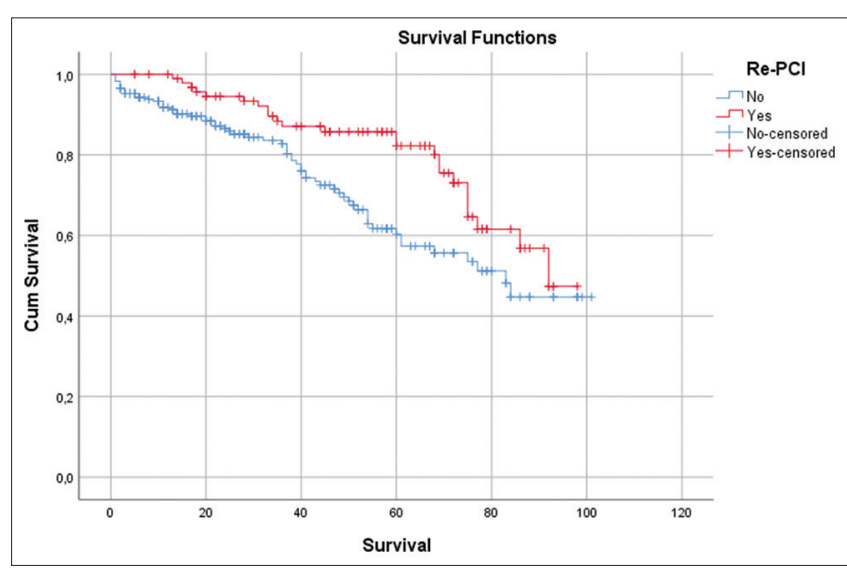

Figure 11: Re-do revascularization and survival

Coronary revascularization before or after carotid stenting?

Regarding this debatable but practically important question, we found that patients with coronary revascularization before CAS (74 months) had a higher

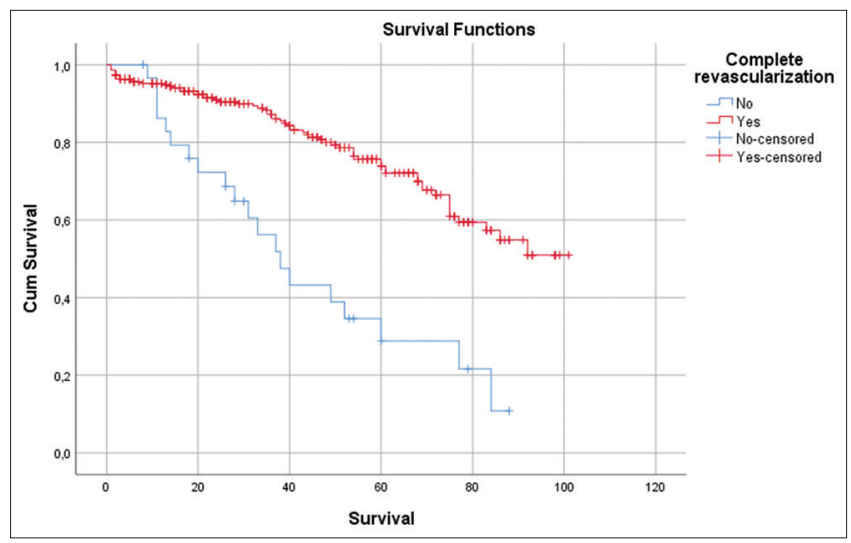

Figure 12: Degree of revascularization and survival

survival rate than those with revascularization after CAS (60 months) $\left(\chi^{2}=5.306, p=0.018\right)$ (Figure 13).

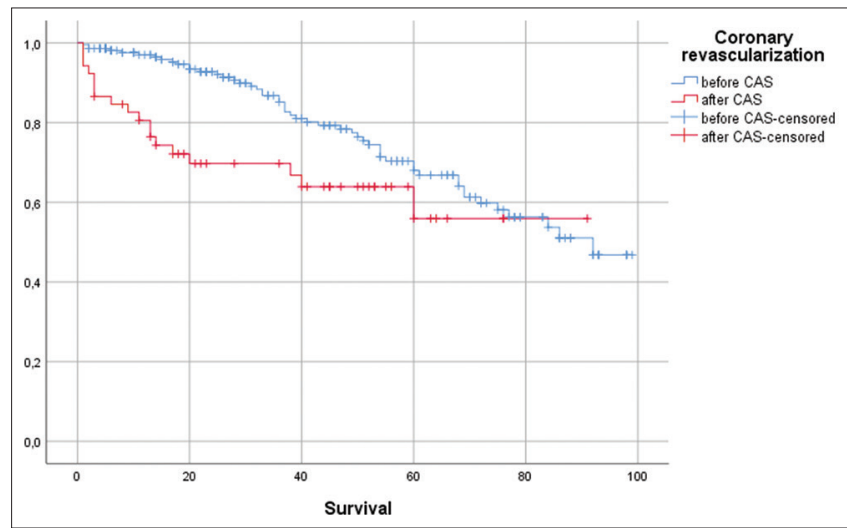

Figure 13: Percutaneous coronary intervention before/after carotid artery stenting - survival rate

Concomitant heart disease. Ejection fraction (EF) and HF

Depending on the value of $E F$, patients were divided into three groups: With normal $\mathrm{EF} \geq 55 \%$, slightly to moderately reduced EF $36-54 \%$, and severely reduced EF $\leq 35 \%$. There was a statistically significant difference $\left(\chi^{2}=21.349, p=0.000\right)$, namely, a progressively decreasing MSR in the three groups, respectively: Unattainable MS in normal EF, 69 with moderately reduced EF and 43 months in patients with severely reduced EF (Figure 14).

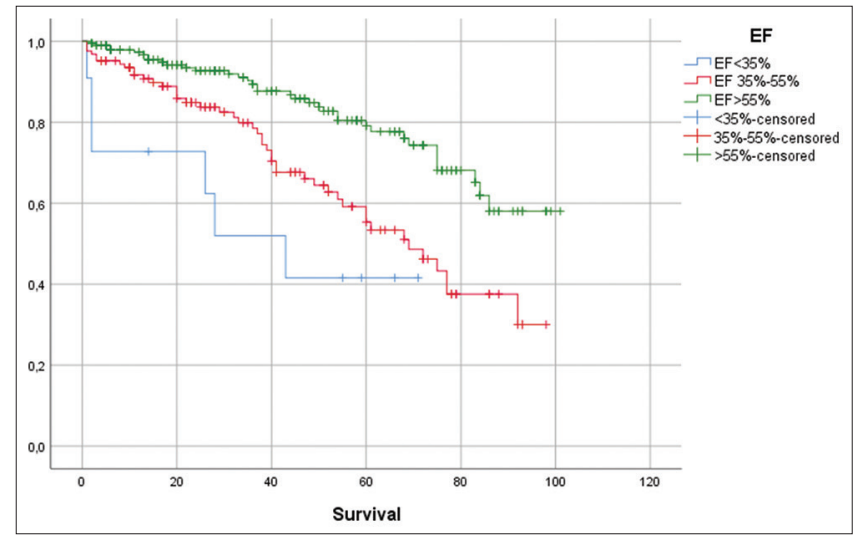

Figure 14: Ejection fraction and survival rate

The results are similar when analyzed in terms of $\mathrm{HF}$ : MSR in patients with HF was 60 months, and MSH in those without $\mathrm{CH}$ is unattainable $\left(\chi^{2}=35.539, \mathrm{p}=\right.$ 0.000) (Figure 15).

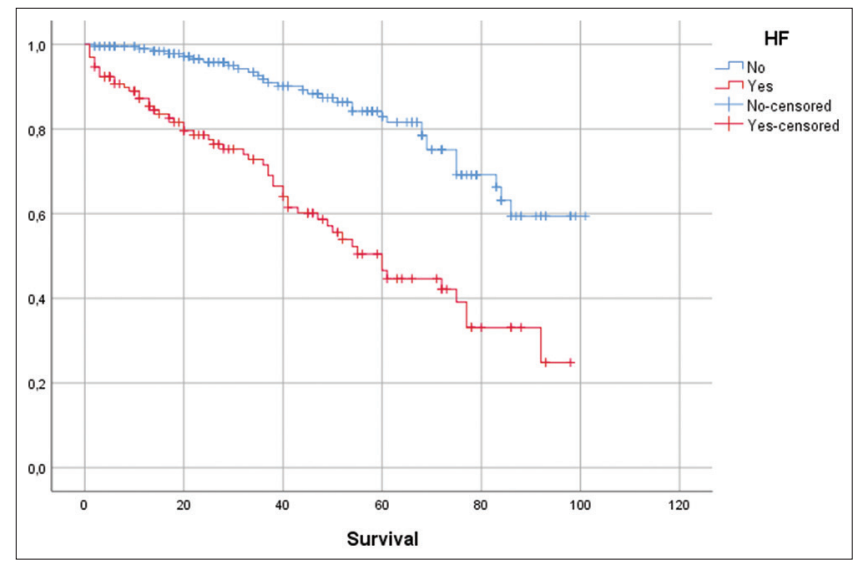

Figure 15: Heart failure and survival rate

Valvular heart disease, permanent pacemaker, and atrial fibrillation (FA)

In patients with concomitant severe valvular heart disease, MSR was only 61 months, and in the group without valvular pathology - unattainable $\left(\chi^{2}=27.237, p=0.000\right)$ (Figure 16). An interesting fact was that patients with implanted pacemaker had a two-fold reduction in MSR - 41 months, compared to MSR without a permanent pacemaker - 92.0 months $\left(\chi^{2}=13.132, p=0.000\right)$ (Figure 17). The most common arrhythmia in the monitored group of patients - FA did not show a significant influence on survival. 


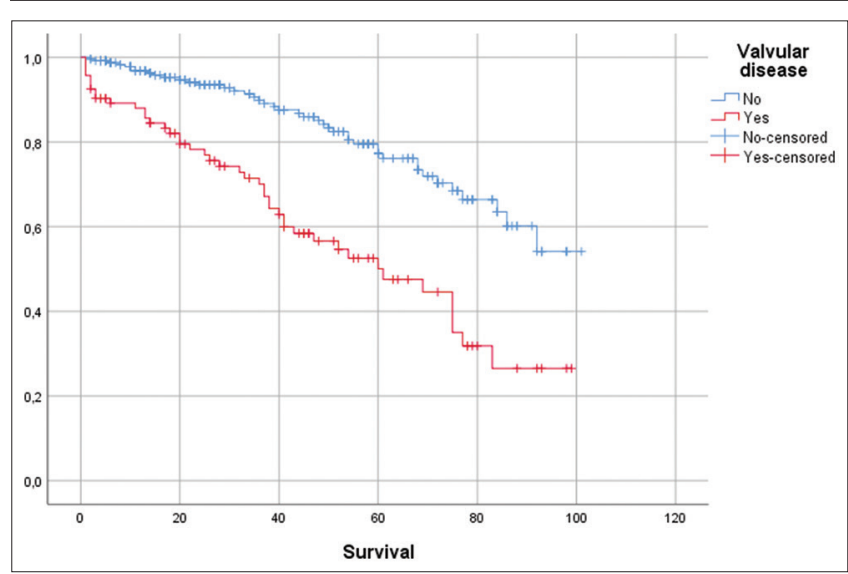

Figure 16: Valvular heart disease and survival rate

Late $\mathrm{Ml}$ and late stroke

Our results show that the impact on survival of lateonset cardiac events such as Ml and stroke is very different. MSR in patients without late MI was unattainable, while in case of MI MSR was significantly reduced -60 months $\left(\chi^{2}=\right.$ 11.118, $p=0.001$ ) and is almost 2 years shorter than MSR of the whole group (Figure 18). However, a late ischemic stroke with MSR of 75 months did not have a significant effect on MSR $\left(\chi^{2}=1.978, p=0.160\right)$ (Figure 19).

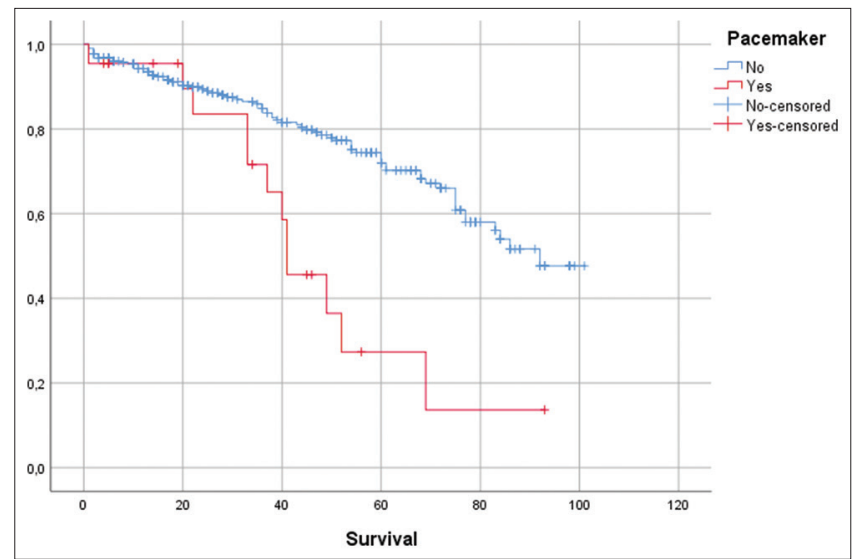

Figure 17: Permanent pacemaker and survival rate

Sex, age, concomitant diseases, and laboratory abnormalities Table 3 are shown in Table 3 (Table 3).

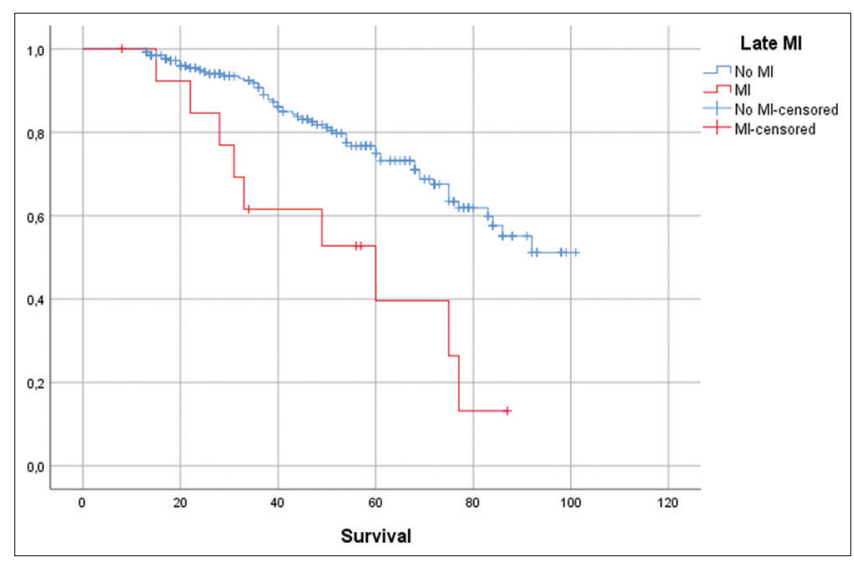

Figure 18: Late miocardial infarction and survival rate
In the analysis of these heterogeneous indicators, the significant risk factors in the prognosis turned out to be CKD $(p<0.000)$, diabetes mellitus

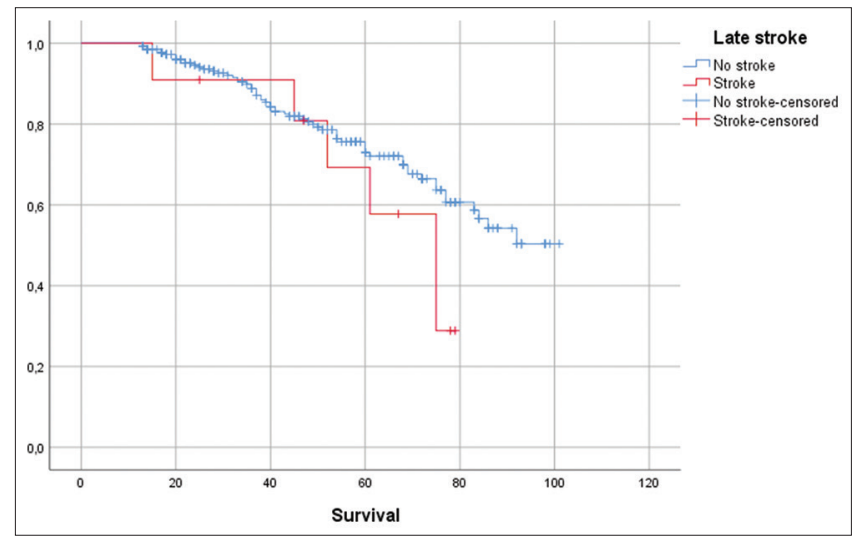

Figure 19: Late ischemic stroke and survival rate

( $p=0.004)$. Of particular interest is a group of 11 patients with residual elevated troponin levels $\geq 0.1$ to 1.0 in whom carotid stenting was performed $<14$ days after acute coronary syndrome (ACS). MSR in the group without elevated troponin was unattainable compared to significantly lower in patients with elevated troponin -20 months $\left(\chi^{2}=15.985, p<\right.$ $0.000)$. Similarly there was lower MSR in patients with hyperfibrinogenemia $\left(\chi^{2}=4.164, p=0.041\right)$.

Combinations with unfavorable prognostic significance

While, in general, FA had no effect on survival, the combination of FA and male gender turned out to lead to a significant reduction in MSR $\left(\chi^{2}=6.656\right.$, $p=0.010)$. Similarly, anemia in a female patient resulted in MSR of 54 months ( $p=0.023)$.

Table 3: MS rate in patients with concomitant disease and biochemical marker deviations

\begin{tabular}{llllll}
\hline Indicator & MSR & $\mathrm{p}$ & Indicator & MSR & $\mathrm{p}$ \\
\hline Hypertriglyceridemia & 83.0 & 0.278 & Anemia & 54.0 & 0.135 \\
Increased LDL levels & 93.0 & 0.955 & PAD & 84.0 & 0.746 \\
Residual increase in troponin levels & 20.0 & 0.000 & COPD & 86.0 & 0.846 \\
CKD & 55.0 & 0.000 & Hypertriglyceridemia & 83.0 & 0.278 \\
Diabetes & 69.0 & 0.004 & Hyperfibrinogenemia & 72.0 & 0.041 \\
\hline PAD: Peripheral artery disease, CKD: Chronic kidney disease, COPD: Chronic obstructive pulmonary \\
disease, LDL: Low-density lipoprotein.
\end{tabular}

Prognostic model for survival in patients with carotid stenosis and interventional revascularization

The great number of diverse statistically significant relations in a huge panel of over 40 indicators cannot contribute to a clear prognostic model. Through a two-step (2 blocks) multifactorial Cox regression analysis, we looked for "independent" prognostic factors for patient survival. In block 1, we included 12 factors with expected significant impact on survival, and in block 2-8 factors with probable prognostic significance. Seven of them turned out to be independent prognostic risk factors (Table 4). 
Table 4: Independent survival prognostic factors in patients after CAS and preceding coronary artery revascularization

\begin{tabular}{|c|c|c|c|c|c|c|c|c|}
\hline \multirow[t]{2}{*}{ Factor } & \multirow[t]{2}{*}{ B } & \multirow[t]{2}{*}{ SE } & \multirow[t]{2}{*}{ Wald } & \multirow[t]{2}{*}{ df } & \multirow[t]{2}{*}{ Sig. } & \multirow[t]{2}{*}{$\operatorname{Exp}(\mathrm{B})$} & \multicolumn{2}{|c|}{$\begin{array}{l}95.0 \% \mathrm{Cl} \text { for } \\
\operatorname{Exp}(\mathrm{B})\end{array}$} \\
\hline & & & & & & & Lower & Upper \\
\hline LM_disease & -0.844 & 0.278 & 9.198 & 1 & 0.002 & 0.430 & 0.249 & 0.742 \\
\hline Complete revascularization & 0.682 & 0.331 & 4.258 & 1 & 0.039 & 1.978 & 1.035 & 3.782 \\
\hline Late MI & -1.112 & 0.408 & 7.419 & 1 & 0.006 & 0.329 & 0.148 & 0.732 \\
\hline Previous stroke & -0.921 & 0.268 & 11.856 & 1 & 0.001 & 0.398 & 0.236 & 0.672 \\
\hline Age above 70 & -1.027 & 0.300 & 11.747 & 1 & 0.001 & 0.358 & 0.199 & 0.644 \\
\hline Valvular heart disease & -1.001 & 0.267 & 14.014 & 1 & 0.000 & 0.367 & 0.218 & 0.621 \\
\hline Carotid score & -0.535 & 0.271 & 3.915 & 1 & 0.048 & 0.585 & 0.344 & 0.995 \\
\hline
\end{tabular}

\section{Discussion}

In specialized literature, the effectiveness of CAS and its complications have been analyzed for decades in numerous randomized clinical trials (RCTs) among a huge cohort of patients. Almost all older RCTs and national registries, as well as meta-analyzes from the CREST, EVA-3S, SPACE, ICSS studies, generally documented a higher incidence of periprocedural stroke by day 30 , especially in adult patients over 70 years of age treated with CAS [13] In recent years, in parallel with the improvement of interventional methods, data from similar studies show comparable results and no difference in long-term follow-up [14], [15]. In 2017 Sardar et al. in a meta-analysis - CAS versus CEA of 5 RCTs including 6526 patients, found no differences between the two revascularization methods (OR 1.22; 95\% Cl: 0.94-1.59) in terms of periprocedural complications and ipsilateral stroke on follow-up for 5.3 years [16]. CAS is established as an effective procedure with strict indications and generally accepted intervention protocols [17], [18]. All studies, both earlier and present lead to one conclusion: It is not the neurological complications but rather $\mathrm{CHD}$ and cardiovascular pathology that influence early and late complications and lead to reduction in survival following CAS and CEA [19], [20], [21].

Taking into account the literature data, the systemic nature of the atherosclerotic process and the characteristics of the studied group of patients, we analyzed the risk factors in patients with indications for CAS and concomitant coronary stenosis. All our patients underwent one-stage selective coronary and carotid angiography and in indications - PCl/CABG before CAS, as an attempt to minimize the negative role of CHD and cardiac pathology, that is, to increase the benefits of CAS in the short and long term. Pre-carotid angiography, according to a series of publications by Illuminati et al., is the only independent variable that not only predicts the occurrence of post-operative coronary ischemia, but also reduces the likelihood of cardiac ischemia 4-fold after CEA [22], [23]. Similar protocol, officially Class IIb in recommendations, was found appropriate in our patients, $87.2 \%$ of whom were assessed as complex high-risk mainly due to cardiocerebral and other cardiovascular pathology, and last but not least pronounced comorbidity (Tables 1 and 2). Our incidence of accompanying CHD was higher than this cited in literature. According to Kallikazaros et al., the incidence of carotid stenosis $>50 \%$ increases from $5 \%$ in patients with singlevessel coronary artery disease (CAD) to $40 \%$ in the presence of LM disease [24]. According to Hoffman et al., coronary stenosis $\geq 50 \%$ in patients indicated for elective carotid stenting is $77.1 \%$ [12], and according to Enomoto et al. 49.1\% [25]. Predictive correlations between the presence of carotid stenosis and high Syntax and Gensini scores were also sought. Avci et al. found a positive correlation between Syntax score I, three-vessel disease, and carotid stenosis [26]. A similar correlation between the intima-media thickness of the carotid artery and Syntax score I and II was reported by the teams of Saedi et al., Ikeda et al., Aksu et al., and Korkmaz et al. [27], [28], [29], [30]. The results of Ozturk and Sahin and Costanzo et al. and col [31], [32], [33] are opposing. Despite the various incidences cited above, the combination of carotid and coronary atherosclerosis is an indisputable clinical fact. It is no coincidence that CS $>50 \%$ show increased risk for $\mathrm{CHD}$ and are considered equivalent to the above [34], [35]. In patients with symptomatic or asymptomatic carotid stenosis, the presence of CHD increases the risk of vascular cardiocerebral complications during long-term follow-up [21], [36], [37].

We assessed the prognostic prospect of four groups of risk factors which are among the most frequently cited in the specialized literature with regards to complications in revascularization procedures [20], [38]. They were pre-tested by single-factor and multi-factor analysis, through which we confirmed a reliable correlation or predictive correlation between them and the most important adverse events in the course of follow-up. Through the adopted stepwise revascularization protocol (CAS after $\mathrm{PCI}$ ), we did not find a significant difference in MSR among 287 comprehensively assessed high-risk patients compared to the others at standard risk and between a group with angiographically proven CHD (299 patients) and A group without CHD. There is not much difference in the number of patients - CHD is the most common comorbidity in high-risk patients with concomitant disease, organ dysfunction and biochemical abnormalities. Respectively, the MSRs are similar and insignificantly lower than the MSRs (86 months) for the whole group - 83 months for the high-risk group and 84 months for the patients with previous coronary intervention. In the absence of coronary revascularization, Arif et al. stated that "the presence of CHD was accompanied by $22 \%$ mortality after CAS, compared to $0 \%$ in the group without $\mathrm{CHD}$ at follow-up of $71.9 \pm 31.7$ months" [36]. In a significant group of patients The European Carotid Surgery Trial study also shows that coronary heart death in patients with carotid stenosis reaches $30 \%$ over a period of 10 years [39]. 
Our findings also support the idea of the main role of cardiac pathology in the long run regarding patients with carotid and CAD: Unlike late MI, late stroke does not have a significant effect on survival.

In terms of prognosis, among the various indicators characterizing carotid pathology, it turned out that a high carotid score of 5-9 points, stroke and bilateral carotid stenosis correlate with lower MS. In the CREST study, perioperative stroke was also associated with three times worse long-term survival [40] as far as other indicators are concerned, symptoms, the type of implanted carotid stent and carotid restenosis did not show statistical significance.

In the second group of tested indicators, characterizing CHD, significantly lower survival was registered in LM disease (54 months), in Gensini score $>70$ (68 months), and Syntax score >32 (55 months). An important result and indirect proof of the importance and necessity of preliminary revascularization of $\mathrm{CHD}$ is the high statistical significance of low MSR - 38 months in patients with incomplete coronary revascularization $\left(\chi^{2}=\right.$ $28.215, p<0.000)$. The presence of coronary pathology, especially untreated, compromises the results of CAS. Even among the general population stroke patients and the presence of CHD, indicate an incidence of $24 \%$ for cardiovascular events over a period of 2 years, according to Amarenco et al. Cardiac pathology (exception granted for AF) such as HF, low EF, valvular heart disease, and permanent pacemaker also turned out to be negative prognostic factors in terms of survival.

Concomitant diseases and biochemical abnormalities with prognostic significance for survival were only CKD, diabetes mellitus and residual elevated troponin in patients with previous $\mathrm{PCl}$ up to 14 days after ACS. CKD and DM are known and discussed in the literature negative prognostic conditions due to critical organ dysfunction and their frequent combinations with other risk factors [20]. The first positive results of preliminary coronary revascularization in atherosclerotic changes in other vascular areas subject to surgery were reported more than 40 years ago by Hertzer et al. [41]. Despite reasonable remarks on patient selection, two studies CARP [42] and DECREASE-V [43] not only did not reveal perioperative and long-term benefit from preliminary coronary revascularization, but also had a serious negative impact worldwide. Only in 2009 Monaco et al. in a prospective study refute the negative trend and point out that routine preoperative coronary angiography and selective $\mathrm{PCl}$ provide better long-term and eventfree survival in patients needing vascular surgery [44]. Optimal behavior in patients with both carotid and $\mathrm{CAD}$ is still controversial. Four possible strategies are applied - simultaneous or stepwise CABG and CAS, CABG and CEA, PCl and CEA, and $\mathrm{PCl}$ and CAS. The results, however, are very confusingly different: The risk of stroke/death in simultaneous CEA and CABG is highest and lowest in a stepwise approach [45], [46]; in a registry of 27,084 patients in the CAS-CABG versus CEA-CABG strategies, the incidence of postoperative stroke was
$2.4 \%$ versus $3.9 \%(p<0.001)$ and of stroke/death $6.9 \%$ versus $8.6 \%(p=0.1)$ [47]; according to Versaci et al. CAS immediately before CABG gives promising results with a low incidence of death/stroke [48]; 132 patients treated with CAS and CABG on the same day had an in-hospital stroke rate of $0.75 \%$ and a 5 - and 10 -year period free from neurological events of $95 \%$ and $85 \%$, respectively; analysis in 350 patients with staged CEA, followed up to 90 days after CABG showed the worst results for Ml between revascularization stages [49]. In recent studies by the teams of Sulženko [19] (2019), Kumar et al. [50] (2020), Shen et al. [51], Manthey et al. [52] (2020), Tzoumas et al. [53] (2020) results and opinions are mixed, but the need to utilize the effect of CEA/CAS in underlying coronary stenosis by revascularization of both vascular areas is a common opinion. Addressing this problem, our results in high-risk patients show that stepwise $\mathrm{PCl}$ before CAS yields significantly better MS than revascularization after CAS $\left(\chi^{2}=5.306, p=0.018\right)$. Please add strengths and limitations of this study.

\section{Conclusion}

In the study, we focus mainly on the importance of risk factors for the prognosis and survival of patients with carotid and coronary disease after interventional revascularization. In practice, this is the final assessment of the efficiency and effectiveness of any revascularization procedure in any vascular pool. Unfortunately, RCTs are missing so far, and the assessment of each of the risk factors for survival is rare. Insufficient literature data and a very heterogeneous patient population in the individual publications make it difficult to correctly compare our results, which we present cautiously. In modern times, it is still difficult to determine the "ideal" revascularization strategy for carotid and coronary stenosis. Our results show not only the frequent combination between them, but also the possibility of increasing the benefit of CAS by minimizing the effects of concomitant CHD and vascular pathology. The proposed survival model identified by multivariate Cox regression analysis identified the following independent prognostic factors: LM disease, complete revascularization, late MI, stroke, age above 70 years, valvular heart disease, and carotid score. They require a complex therapeutic approach, both before and after the revascularization procedure during the follow-up period.

\section{References}

1. Tityanova E, Stamenova P, Grigorov K, Petrov I, Velcheva I, et al. National Consensus Document for Ultrasound Diagnosis and Treatment of Extracranial Carotid Disease, Sofia, Coty Ltd; 2011. 
2. Stilo F, Montelione N, Calandrelli R, Distefano M, Spinelli F, Di Lazzaro $\mathrm{V}$, et al. The management of carotid restenosis: A comprehensive review. Ann Transl Med. 2020;8(19):1272. https://doi.org/10.21037/atm-20-963 PMid:33178804

3. Petersen S, Peto V, Rayner M, Leal J, Luengo-Fernandez R, Gray A. European Cardiovascular Disease Statistics. London: BHF; 2005.

4. Prati P, Vanuzzo D, Casaroli M, Di Chiara A, De Biasi F, Feruglio GA, et al. Prevalence and determinants of carotid atherosclerosis in a general population. Stroke. 1992;23(12):1705-11. https://doi.org/10.1161/01.str.23.12.1705 PMid:1448818

5. O'Leary DH, Polak JF, Kronmal RA, Kittner SJ, Bond MG, Wolfson SK Jr., et al. Distribution and correlates of sonographically detected carotid artery disease in the cardiovascular health study. The CHS collaborative research group. Stroke. 1992;23(12):1752-60. https://doi.org/10.1161/01.str.23.12.1752 PMid:1448826

6. Touzé E, Varenne O, Calvet D, Mas JL. Coronary risk stratification in patients with ischemic stroke or transient ischemic stroke attack. Int J Stroke. 2007;2(3):177-83. https:// doi.org/10.1111/j.1747-4949.2007.00136.x

PMid:18705941

7. Honda O, Sugiyama S, Kugiyama K, Fukushima $\mathrm{H}$, Nakamura S, Koide S, et al. Echolucent carotid plaques predict future coronary events in patients with coronary artery disease. J Am Coll Cardiol. 2004;43(7):1177-84. https://doi.org/10.1016/j. jacc.2003.09.063

PMid:15063426

8. Alberts MJ, Bhatt DL, Mas JL, Ohman EM, Hirsch AT, Röther J, et al Three-year follow-up and event rates in the international reduction of atherothrombosis for continued health registry. Eur Heart J. 2009;30(19):2318-26. https://doi.org/10.1093/eurheartj/ehp355 PMid:19720633

9. Hertzer NR, Young JR, Beven EG, Graor RA, O'Hara PJ, Ruschhaupt WF $3^{\text {rd }}$, et al. Coronary angiography in 506 patients with extracranial cerebrovascular disease. Arch Intern Med. 1985;145(5):849-52.

PMid:3994461

10. Cohen SN, Hobson RW II, Weiss DG, Chimowitz M. Death associated with asymptomatic carotid artery stenosis: Longterm clinical evaluation. VA cooperative study 167 group. J Vasc Surg. 1993;18(6):1002-9; discussion 1009-11.

PMid:8264028

11. Pieniazek P, Musialek $P$, Kablak-Ziembicka A, Tekieli L, Motyl R, Przewlocki T, et al. Carotid artery stenting with patient-and lesiontailored selection of the neuroprotection system and stent type: Early and 5-year results from a prospective academic registry of 535 consecutive procedures (TARGET-CAS). J Endovasc Ther. 2008;15(3):249-62. https://doi.org/10.1583/07-2264.1 PMid:18540694

12. Hofman R, Kypta A, Steinwender C, Kerschner K, Grund M, Leisch $\mathrm{F}$. Coronary angiography in patients undergoing carotid artery stenting shows a high incidence of significant coronary artery disease. Heart. 2005;91(11):1438-41. https://doi. org/10.1136/hrt.2004.050906

\section{PMid:15761052}

13. Howard G, Roubin GS, Jansen O, Hendrikse J, Halliday A Fraedrich $\mathrm{G}$, et al. Association between age and risk of stroke or death from carotid endarterectomy and carotid stenting: A meta-analysis of pooled patient data from four randomised trials. Lancet. 2016;387(10025):1276. https://doi.org/10.1016/ S0140-6736(15)01309-4

PMid:26880122
14. Bonati LH, Dobson J, Featherstone RL, Ederle J, van der Worp HB, de Borst GJ, et al. Long-term outcomes after stenting versus endarterectomy for treatment of symptomatic carotid stenosis: The international carotid stenting study (ICSS) randomised trial. Lancet. 2015;385(9967):529-38. https://doi. org/10.1016/S0140-6736(14)61184-3

PMid:25453443

15. BrottTG, Howard G, Roubin GS, Meschia JF, MackeyA, Brooks W, et al. Long-term results of stenting versus endarterectomy for carotid-artery stenosis. N Engl J Med. 2016;374(11):1021-31. https://doi.org/10.1056/NEJMoa1505215

PMid:26890472

16. Huynh K. Atherosclerosis: Carotid artery stenting versus endarterectomy-no difference in long-term outcomes. Nat Rev Cardiol. 2014;11(12):685. https://doi.org/10.1038/nrcardio.2014.174 PMid:25367651

17. Weiss N, Gerber J, Reeps C. Carotis stenosis: Stenting is eqivalent to endarteriectomy in the long term. Dtsch Med Wochenschr. 2016;141(10):678-9. https://doi.org/10.1055/s-0042-103717 PMid:27176057

18. Gray WA, Chaturvedi S, Verta P, Investigators and the Executive Committees. Thirty-day outcomes for carotid artery stenting in 6320 patients from 2 prospective, multicenter, high-surgical-risk registries. Circ Cardiovasc Interv. 2009;2(3):159-66. https://doi. org/10.1161/CIRCINTERVENTIONS.108.823013

PMid:20031712

19. Sulženko J, Paluszek P, Machnik R, Widimský P, Jarkovský J, Pieniazek P. Prevalence and predictors of coronary artery disease in patients undergoing carotid artery stenting. Coron Artery Dis. 2019;30(3):204-10. https://doi.org/10.1097/ MCA.0000000000000695

PMid:30741742

20. AbuRahma AF. Predictors of perioperative stroke/death after carotid artery stenting: A review article. Ann Vasc Dis. 2018;11(1):15-24. https://doi.org/10.3400/avd.ra.17-00136 PMid:29682104

21. Veselka J, Špaček M, Horváth M, Štěchovský C, Homolová I, Zimolová $\mathrm{P}$, et al. Impact of coexisting multivessel coronary artery disease on short-term outcomes and long-term survival of patients treated with carotid stenting. Arch Med Sci. 2016;12(4):760-5. https://doi.org/10.5114/aoms.2016.60964 PMid:27478456

22. Illuminati G, Ricco JB, Greco C, Mangieri E, Calio' F, Ceccanei G, et al. Systematic preoperative coronary angiography and stenting improves postoperative results of carotid endarterectomy in patients with asymptomatic coronary artery disease: A randomised controlled trial. Eur J Vasc Endovasc Surg. 2010;39(2):139-45. https://doi.org/10.1016/j. ejvs.2009.11.015 PMid:20005750

23. Illuminati G, Schneider F, Greco C, Mangieri E, Schiariti M, Tanzilli G, et al. Long-term results of a randomized controlled trial analyzing the role of systematic pre-operative coronary angiography before elective carotid endarterectomy in patients with asymptomatic coronary artery disease. Eur J Vasc Endovasc Surg. 2015;49(4):366-74. https://doi.org/10.1016/j. ejvs.2014.12.030 PMid:25701070

24. Kallikazaros I, Tsioufis C, Sideris S, Stefanadis C, Toutouzas P. Carotid artery disease as a marker for the presence of severe coronary artery disease in patients evaluated for chest pain. Stroke. 1999;30(5):1002-7. https://doi.org/10.1161/01. str.30.5.1002 PMid:10229735

25. Enomoto Y, Yoshimura S, Yamada K, Kawasaki M, Nishigaki K, 
Minatoguchi S, et al. Silent coronary artery disease in Japanese patients undergoing carotid artery stenting. J Stroke Cerebrovasc Dis. 2013;22(7):1163-8. https://doi.org/10.1016/j. jstrokecerebrovasdis.2012.12.013 PMid:23352686

26. Avci A, Fidan S, Tabakçı MM, Toprak C, Alizade E, Acar E, et al. Association between the gensini score and carotid artery stenosis. Korean Circ J. 2016;46(5):639-45. https://doi. org/10.4070/kcj.2016.46.5.639

PMid:27721854

27. Saedi S, Ghadrdoost B, Pouraliakbar H, Zahedmehr A, Jebelli $A$. The association between increased carotid intimamedia thickness and SYNTAX Score in coronary artery disease: A single center study. Indian Heart J. 2018;70(5):627-9. https:// doi.org/10.1016/j.ihj.2018.01.010

PMid:30392499

28. Ikeda N, GuptaA, Dey N, BoseS, ShafiqueS,ArakT, etal. Improved correlation between carotid and coronary atherosclerosis SYNTAX score using automated ultrasound carotid bulb plaque IMT measurement. Ultrasound Med Biol. 2015;41(5):1247-62. https://doi.org/10.1016/j.ultrasmedbio.2014.12.024 PMid:25638311

29. Aksu U, Gulcu O, Bilgi Z, Topcu S, Sevimli S, Bayram E, et al. The association of the syntax Score II with carotid intima media thickness and epicardial fat tissue. Indian Heart J. 2017;69(6):752-6. https://doi.org/10.1016/j.ihj.2017.04.008 PMid:29174253

30. Korkmaz L, Bektas H, Korkmaz AA, Agaç MT, Acar Z, Erkan H, et al. Increased carotid intima-media thickness is associated with higher SYNTAX score. Angiology. 2012;63(5):386-9. https://doi.org/10.1177/0003319711419837 PMid:21948972

31. Ouriel K, Hertzer NR, Beven EG, O'hara PJ, Krajewski LP, Clair DG, et al. Preprocedural risk stratification: Identifying an appropriate population for carotid stenting. J Vasc Surg. 2001;33(4):728-32. https://doi.org/10.1067/mva.2001.111981 PMid:11296324

32. Ozturk S, Sahin M. Syntax Score I and II for predicting carotid artery stenosis in patients with multivessel coronary artery disease: A propensity score matching analysis. Braz J Cardiovasc Surg. 2019;34(6):653-8. https://doi.org/10.21470/1678-9741-2019-0067 PMid:31545581

33. Costanzo L, Campisano MB, Capodanno D, Sole A, Grasso C, Ragusa M, et al. The SYNTAX score does not predict presence of carotid disease in a multivessel coronary disease population. Catheter Cardiovasc Interv. 2014;83(7):1169-75. https://doi. org/10.1002/ccd. 25320

PMid:24323404

34. Tearney G, Yabushita H, Houser SL,Aretz HT, Jang IK, SchlendorfKH, et al. Quantification of macrophage content in atherosclerotic plaques by optical coherence tomography. Circulation. 2003;107:113-9. https://doi.org/10.1161/01.cir.0000044384.41037.43

PMid:12515752

35. Sulženko J, Pieniazek P. The cardiovascular risk of patients with carotid artery stenosis. Cor Vasa. 2018;60(1):e42-8. https://doi. org/10.1016/j.crvasa.2017.09.006

36. Arif $S$, Bartuś $S$, Dziewierz A, Chyrchel M, Brzeziński M, Rakowski T, et al. Impact of coronary artery disease presence on the long-term follow-up of carotid artery stenting. Kardiol Pol. 2015;73(4):274-9. https://doi.org/10.5603/KP.a2014.0217 PMid:25371310

37. Hoshino M, Kawai H, Sarai M, Sadato A, Hayakawa M, Motoyama S, et al. Noninvasive assessment of stenotic severity and plaque characteristics by coronary CT angiography in patients scheduled for carotid artery revascularization. J Atheroscler
Thromb. 2018;25(10):1022-31. https://doi.org/10.5551/jat.42176 PMid:29459518

38. DuaA, Romanelli BS, Upchurch GR Jr, Pan J, Hood D, Hodgson KJ et al. Predictors of poor outcome after carotid intervention. J Vasc Surg. 2016;64(3):663-70. https://doi.org/10.1016/j.jvs.2016.03.428 PMid:27209401

39. Gray WA, Hopkins LN, Yadav S, Davis T, Wholey M, Atkinson R, et al. Protected carotid stenting in high-surgical-risk patients: The ARCHeR results. J Vasc Surg. 2006;44(2):258-68. https:// doi.org/10.1016/j.jvs.2006.03.044

PMid: 16890850

40. Amarenco P, Lavallée PC, Labreuche J, Ducrocq G, Juliard JM, Feldman L, etal. Coronaryartery diseaseand risk of majorvascular events after cerebral infarction. Stroke. 2013;44(6):1505-11. https://doi.org/10.1161/Strokeaha.111.000142 PMid:23598520

41. Hertzer NR, Young JR, Kramer JR, Phillips DF, deWolfe VG, Ruschhaupt WF $3^{\text {rd }}$, et al. Routine coronary angiography prior to elective aortic reconstruction: Results of selective myocardial revascularization in patients with peripheral vascular disease. Arch Surg. 1979;114(11):1336-44. https://doi.org/10.1001/ archsurg.1979.01370350138018

PMid:496636

42. McFalls EO, Ward HB, Moritz TE, Goldman S, Krupski WC Littooy F, et al. Coronary-artery revascularization before elective major vascular surgery. N Engl J Med. 2004;351(27):2795-804. https://doi.org/10.1056/NEJMoa041905 PMid:15625331

43. Poldermans D, Schouten O, Vidakovic R, Bax JJ, Thomson IR, Hoeks SE, et al. A clinical randomized trial to evaluate the safety of a noninvasive approach in high-risk patients undergoing major vascular surgery. J Am Coll Cardiol. 2007;49(17):1763-9. https://doi.org/10.1016/j.jacc.2006.11.052

PMid: 17466225

44. Monaco M, Stassano P, di Tommaso L, Pepino P, Giordano A, Pinna GB, et al. Systematic strategy of prophylactic coronary angiography improves long-term outcome after major vascular surgery in medium-to high-risk patients: A prospective study. J Vasc Surg. 2009;44(2):258-68. https://doi.org/10.1016/j.jacc.2009.05.041 PMid:19729114

45. Ricotta JJ, Char DJ, Cuadra SA, Bilfinger TV, Wall LP, Giron F, et al. Modeling stroke risk after coronary artery bypass and combined coronary artery bypass and carotid endarterectomy. Stroke. 2003;34(5):1212-7. https://doi.org/10.1161/01. STR.0000069263.08070.9F

PMid:12690211

46. Naylor AR, Cuffe RL, Rothwell PM, Bell PR. A systematic review of outcomes following staged and synchronous carotid endarterectomy and coronary artery bypass. Eur J Vasc Endovasc Surg. 2003;25(5):380-9. https://doi.org/10.1053/ejvs.2002.1895 PMid: 12713775

47. Timaran $\mathrm{CH}$, Rosero EB, Smith ST, Valentine RJ, Modrall JG, Clagett GP. Trends and outcomes of concurrent carotid revascularization and coronary bypass. JVasc Surg. 2008;48(2):35560; discussion 360-1. https://doi.org/10.1016/j.jvs.2008.03.031 PMid:18572353

48. Versaci F, Del Giudice C, Scafuri A, Zeitani J, Gandini R, Nardi $\mathrm{P}$, et al. Sequential hybrid carotid and coronary artery revascularization: Immediate and mid-term results. Ann Thorac Surg. 2015;99:1305-12.

49. Chiariello LP, Pellegrino A, Saitto G, Chiariello GA, Russo M, Zeitani J, et al. Simultaneous carotid artery stenting and heart surgery: Expanded experience of hybrid surgical procedures. Ann Thorac Surg. 2015;99(4):1291-7. https://doi.org/10.1016/j. athoracsur.2014.11.043 
PMid:25661578

50. Kumar S, McDaniel M, Samady H, Forouzandeh F Contemporary revascularization dilemmas in older adults. J Am Heart Assoc. 2020;9(3):e014477. https://doi.org/10.1161/ jaha.119.014477

PMid:31973608

51. Shen Y, Jin S, Lin C, Shen J, Hong Z, Xue S, et al. Safety of different carotid artery revascularization strategies in the coronary artery bypass graft population: Study protocol for a systematic review and network meta-analysis. Ann Transl Med. 2020;8(23):1605. https://doi.org/10.21037/ atm-20-4451

PMid:33437804
52. Manthey S, Spears J, Goldberg S. Coexisting coronary and carotid artery disease-which technique and in which order? Case report and review of literature. Clin Med Insights Cardiol. 2020;14:1179546820951797. https://doi. org/10.1177/1179546820951797.

PMid:32922112

53. Tzoumas A, Giannopoulos S, Texakalidis P, Charisis N, Machinis T, Koullias GJ. Synchronous versus staged carotid endarterectomy and coronary artery bypass graft for patients with concomitant severe coronary and carotid artery stenosis: A systematic review and meta-analysis. Ann Vasc Surg. 2020;63:427-38.e1. https://doi.org/10.1016/j.avsg.2019.09.007 PMid:31629126

Author Queries???

AQ6: Please follow this format for applicable kind of reference. 